\title{
Preliminary crystallographic study of CD38 in complex with isatuximab, an FDA-approved antibody drug for treating multiple myeloma
}

\author{
Hyun Tae Lee, Yujin Kim, Ui Beom Park, Tae Jun Jeong and Yong-Seok Heo* \\ Department of Chemistry, Konkuk University, Seoul 05029, Republic of Korea \\ ${ }^{*}$ Correspondence: ysheo@konkuk.ac.kr
}

CD38 is a type II transmembrane glycoprotein highly expressed in diverse hematologic malignancies including B-cell nonHodgkin lymphoma and multiple myeloma cells. CD38 overexpressed on the surface of multiple myeloma cells has been highlighted as a good target for therapeutic agents. In 2020, the US FDA approved isatuximab, an anti-CD38 monoclonal antibody, for the treatment of multiple myeloma. Here, the recombinant proteins of the ectodomain of CD38 and the Fab fragment of isatuximab were expressed, and their binding complex was purified and crystallized. The crystal diffracted to $1.90 \AA$ resolution and belonged to the space group $C 2$, with unit cell parameters $a=217.75, b=43.17, c=81.73 \AA$, and $\beta$ $=103.75^{\circ}$. An asymmetric unit of the crystal contains one molecule of the complex with a VM of $2.33 \AA^{3} \mathrm{Da}^{-1}$ and a solvent content of $47.31 \%$.

\section{INTRODUCTION}

CD38 is an extracellular enzyme expressing both ADP-ribosyl cyclase and cADPR hydrolase activities that generate cyclic adenosine diphosphate (ADP)-ribose ADP ribose (ADPR) and nicotinic acid adenine dinucleotide phosphate from extracellular nicotinamide adenine dinucleotide (NAD+) and cytoplasmic nicotinamide adenine dinucleotide phosphate (NADP), thereby producing metabolite that induces intracellular calcium mobilization. This enzyme is expressed on most thymocytes, some activated peripheral blood $\mathrm{T}$ and $\mathrm{B}$ lymphocytes, plasma cells, NK cells, and DCs. CD38 also functions in cell adhesion, signal transduction, and calcium signaling (Bonello et al., 2018).

Multiple myeloma is hematological cancer characterized by the proliferation of malignant plasma cells in the bone marrow, resulting in the destruction of bone tissue. Immunomodulatory drugs and proteasome inhibitors, such as pomalidomide and carfilzomib, have been used to prolong the survival rates of this disease. Despite the effectiveness of chemotherapy along with autologous stem cell transplantation, the prognosis for patients with multiple myeloma remains poor (Palumbo et al., 2016).

As the expression of CD38 is very high and uniform on myeloma cells, CD38 is a good target for novel therapeutic strategies. Immunotherapy with monoclonal antibodies targeting CD38 has shown to be promising (van de Donk et al., 2018). The anti-tumor effect of anti-CD38 antibodies is related to their ability to induce Antibody-dependent cellular cytotoxicity (ADCC), complement-dependent cytotoxicity (CDC), and antibodydependent cell-mediated cytotoxicity (ADCP) of opsonized CD38+ cells, which are mediated by $\mathrm{FC} \gamma$ receptors (Moreno et al., 2019).

The first anti-CD38 antibody daratumumab (brand name
Darzalex by Janssen Pharmaceuticals) was approved by the U.S. Food and Drug Administration (FDA) in 2015 and by the European Medicines Agency (EMA) in 2016, respectively, for treatment of multiple myeloma (McKeage, 2016). In March 2020, the FDA approved another anti-CD38 antibody Isatuximab (brand name Sarclisa by Sanofi) in combination with pomalidomide and dexamethasone for adult patients with multiple myeloma who have received at least two prior therapies including lenalidomide and a proteasome inhibitor (Dhillon, 2020). Isatuximab can induce direct apoptosis, whereas daratumumab induces apoptosis upon secondary cross-linking (Martin et al., 2019). The epitope mapping of daratumumab using a constrained peptide approach and site-directed mutagenesis showed this antibody binds a unique fine epitope on CD38 (de Weers et al., 2011). The crystal structure of CD38 in complex with SAR650984 revealed its distinct binding site form that of daratumumab (Deckert et al., 2014). Probably, due to the differences in epitopes of these two antibodies, their effectiveness to induce CDC, ADCC, ADCP, or apoptosis varies. Here, we obtained the crystal of the complex of CD38 and the isatuximab Fab, which belongs to the space group C2, and carried out a preliminary crystallographic study to elucidate the exact binding mode and mechanism of action (MOA) of the antibody drug. The exquisite understanding of the MOA of novel antibody drugs can facilitate the design of improved biologics and effective combination therapy in the future.

\section{RESULTS AND DISCUSSION}

The ectodomain of the CD38 protein was expressed using Expi293F mammalian cell expression system and secreted into the culture medium. The Fab fragment of isatuximab was overexpressed in the periplasmic region of Escherichia coli. The 
binding complex of CD38 and the isatuximab Fab was purified to homogeneity by affinity and gel-filtration chromatography (Figure 1A). The crystals of the complex were obtained by a hangingdrop method with a well solution containing $0.2 \mathrm{M}$ Ammonium phosphate monobasic, $0.1 \mathrm{M}$ Tris, 50\% (v/v) 2-Methyl-2,4pentanediol (MPD), $\mathrm{pH} 8.5$ at $20^{\circ} \mathrm{C}$ and their approximate dimensions were $500 \times 70 \times 70 \mu \mathrm{m}$ (Figure 1B). X-ray diffraction data were collected to $1.90 \AA$ resolution and the crystals belonged to space group $C 2$, with unit cell parameters $\mathrm{a}=$ $217.75, b=43.17, c=81.73 \AA$, and $\beta=103.75^{\circ}$. Data collection statistics are provided in Table 1. The Matthews coefficient was calculated to be $2.33 \AA^{3} \mathrm{Da}^{-1}$ with a solvent content of $47.31 \%$ (Matthews, 1968), assuming one complex molecule in an asymmetric unit. After phasing by molecular replacement (MR), we could find that there is one molecule of the binding complex in an asymmetric unit with clear electron density (Figure 2). Further studies to refine the structure of isatuximab in complex with CD38 would elucidate the precise epitope and the molecular mechanism of this antibody drug for the treatment of multiple myeloma.

\section{METHODS}

Expression and purification of the proteins

The DNA sequence for the ectodomain of CD38 (aa 55-300) was synthesized after codon-optimization for human cell expression (Bioneer, Inc). To maximize protein expression, a Kozak sequence was added as well as sequences encoding an exogenous $\mathrm{N}$-terminal signal peptide derived from human IgG1 heavy chain. For easy purification, C-terminal 6xHis-tag was added. The synthesized gene was cloned into a modified pcDNA3.4 vector using Baml and Kpnl restriction sites s (Table 2). CD38 protein was expressed in Expi293F cells grown in suspension using ExpiFectamine ${ }^{\mathrm{TM}} 293$ Transfection Kit (Thermo Fisher Scientific) at $37^{\circ} \mathrm{C}$ in a humidified $8 \% \mathrm{CO} 2$ incubator rotating at $130 \mathrm{rpm}$. Cell culture supernatant was collected five days after transfection and applied to HisTrap HP column (Cytiva)

A

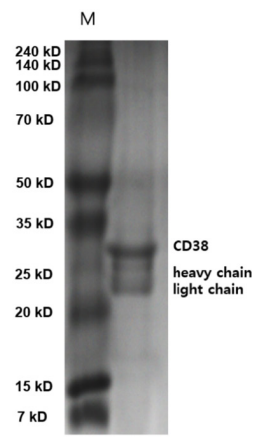

B

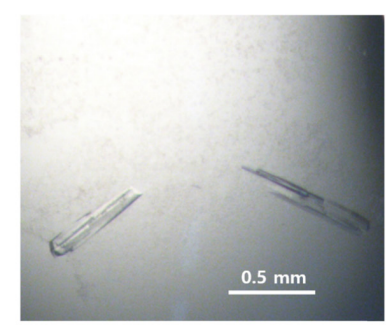

FIGURE 1 I Purification and crystallization of the complex of CD38 and isatuximab Fab. (A) Reducing SDS-PAGE analysis of the purified complex of CD38 and isatuximab Fab fragment containing the heavy and light chain. The lane $\mathrm{M}$ contains molecular-weight marker. (B) Crystals of the binding complex of CD38 and isatuximab Fab grown in $0.1 \mathrm{M}$ Tris, 50\% (v/v) 2-Methyl-2,4pentanediol (MPD), $\mathrm{pH} 8.5$ at $20^{\circ} \mathrm{C}$. and washed with five column volumes of wash buffer $(20 \mathrm{mM}$ Tris, $\mathrm{pH} 8.0,300 \mathrm{mM} \mathrm{NaCl}, 50 \mathrm{mM}$ imidazole). The protein was then eluted with elution buffer $(20 \mathrm{mM}$ Tris, $\mathrm{pH}$ 8.0, $300 \mathrm{mM}$ $\mathrm{NaCl}, 400 \mathrm{mM}$ imidazole). The eluted protein was concentrated for gel filtration chromatography using a HiLoad 16/60 Superdex 200 pg column (Cytiva). The column had previously been equilibrated with gel filtration buffer $(20 \mathrm{mM}$ Tris, $\mathrm{pH}$ 8.0, $300 \mathrm{mM}$ $\mathrm{NaCl})$. The elution profile of the protein showed a single major peak and the protein quality was evaluated by SDS-PAGE.

The DNA sequence for the Fab fragment of isatuximab was synthesized after codon-optimization for expression in $E$. coli (Bioneer, Inc). The sequence contains the heavy and light chain with the STII signal sequence in each chain for periplasmic secretion and a C-terminal 6xHis-tag in the heavy chain (Lee et al., 2016). The synthesized gene was cloned into a modified pBAD vector using Nhel and Apal restriction sites (Table 2).

TABLE 1 | Data collection statistics

\begin{tabular}{ll}
\hline X-ray source & PLS 11C \\
\hline Wavelength $(\AA)$ & 1.0000 \\
\hline Temperature $(\mathrm{K})$ & 100 \\
\hline Rotation range per image $\left({ }^{\circ}\right)$ & 1 \\
\hline Total rotation range $\left(^{\circ}\right)$ & 180 \\
\hline Exposure time per image $(\mathrm{s})$ & 0.5 \\
\hline Space group & $C 2$ \\
\hline a, b, c $(\AA)$ & $217.75,43.17,81.73$ \\
\hline$\alpha, \beta, \gamma()$ & $90,103.75,90$ \\
\hline Resolution range $(\AA)$ & $50.00-1.90(1.93-1.90)^{\star}$ \\
\hline Total No. of reflections & 57741 \\
\hline$R_{\text {sym }}(\%)$ & $7.3(42.5)^{\star}$ \\
\hline$I^{*} \sigma$ & $7.2(2.4)^{\star}$ \\
\hline CC $_{1 / 2}$ & $0.953(0.794)^{\star}$ \\
\hline Completeness $(\%)$ & $98.1(97.4)^{\star}$ \\
\hline Redundancy & $3.4(3.2)^{\star}$ \\
\hline
\end{tabular}

*Values in parentheses are for the outer resolution shell.
A

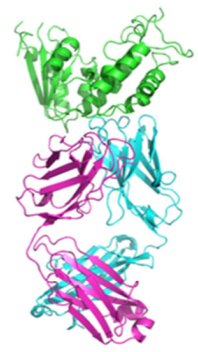

B

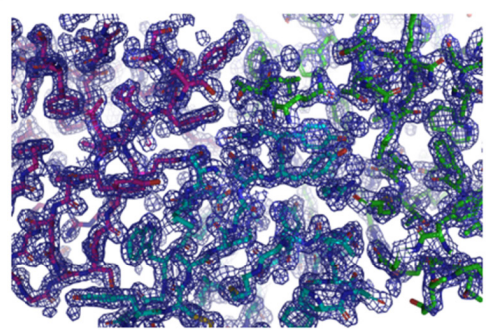

FIGURE 2 I Molecular replacement solution structure of the complex of CD38 and isatuximab. (A) Phasing by molecular replacement revealed that one complex molecule of CD38 and isatuximab Fab exists in an asymmetric unit of the crystals. (B) The 2 fofc map (1.6 $\sigma$ contour level) is shown on the complex during refinement, yielding $R / R_{\text {free }}=0.24 / 0.30$ at $1.90 \AA$ resolution. In $A$ and $B$, the heavy and light chain of isatuximab Fab and CD38 are colored purple, cyan, and green, respectively. 
TABLE 2 | Macromolecule production

\begin{tabular}{|c|c|}
\hline Protein & Isatuximab Fab \\
\hline Source organism & Isatuximab \\
\hline DNA source & Gene synthesis (Bioneer, Inc) \\
\hline Restriction enzyme & Nhel and Apal \\
\hline Cloning vector & pBAD \\
\hline Expression vector & pBAD \\
\hline Expression host & E. coli Top10F \\
\hline $\begin{array}{l}\text { Complete amino- acid } \\
\text { sequence of the } \\
\text { construct produced }\end{array}$ & $\begin{array}{l}\text { <Heavy chain> } \\
\text { QVQLVQSGAEVAKPGTSVKLSCKASGYTFTDYW } \\
\text { MQWVKQRPGQGLEWIGTIYPGDGDTGYAQKFQ } \\
\text { GKATLTADKSSKTVYMHLSSLASEDSAVYYCARG } \\
\text { DYYGSNSLDYWGQGTSVTVSSASTKGPSVFPLA } \\
\text { PSSKSTSGGTAALGCLVKDYFPEPVTVSWNSGAL } \\
\text { TSGVHTFPAVLQSSGLYSLSSWTVPSSSLGTQTY } \\
\text { ICNVNHKPSNTKVDKKVEPKSCDKTHHHHHH } \\
\text { <Light chain> } \\
\text { DIVMTQSHLSMSTSLGDPVSITCKASQDVSTVVA } \\
\text { WYQQKPGQSPRRLIYSASYRYIGVPDRFTGSGA } \\
\text { GTDFTFTISSVQAEDLAVYYCQQHYSPPYTFGGG } \\
\text { TKLEIKRTVAAPSVFIFPPSDEQLKSGTASWCLLN } \\
\text { NFYPREAKVQWKVDNALQSGNSQESVTEQDSK } \\
\text { DSTYSLSSTLTLSKADYEKHKVYACEVTHQGLSS } \\
\text { PVTKSFNRGEC }\end{array}$ \\
\hline Protein & CD38 \\
\hline Source organism & Human \\
\hline DNA source & Gene synthesis (Bioneer, Inc) \\
\hline Restriction enzyme & Baml and Kpnl \\
\hline Cloning vector & pcDNA3.4 \\
\hline Expression vector & pcDNA3.4 \\
\hline Expression host & Expi293F \\
\hline $\begin{array}{l}\text { Complete amino- acid } \\
\text { sequence of the } \\
\text { construct produced }\end{array}$ & $\begin{array}{l}\text { RWRQQWSGPGTTKRFPETVLARCVKYTEIHPEM } \\
\text { RHVDCQSWWDAFKGAFISKHPCDITEEDYQPLM } \\
\text { KLGTQTVPCNKILLWSRIKDLAHQFTQVQRDMFT } \\
\text { LEDTLLGYLADDLTWCGEFATSKINYQSCPDWRK } \\
\text { DCSNNPVSVFWKTVSRRFAEAACDVVHVMLDGS } \\
\text { RSKIFDKDSTFGSVEVHNLQPEKVQTLEAWVIHG } \\
\text { GREDSRDLCQDPTIKELESIISKRNIQFSCKNIYRP } \\
\text { DKFLQCVKNPEDSSCTSEIGTKHHHHHH }\end{array}$ \\
\hline
\end{tabular}

The plasmid pBAD-isatuximab Fab was transformed into $E$. coli Top10F (Invitrogen). The cells were grown at $37^{\circ} \mathrm{C}$ in $\mathrm{LB}$ medium supplemented with $50 \mu \mathrm{g} \mathrm{ml}^{-1}$ ampicillin. When the OD600 of the culture reached 1.0 , the protein expression was induced with $0.2 \%$ arabinose, and cells were grown at $30^{\circ} \mathrm{C}$ for $15 \mathrm{~h}$. The cells were harvested by centrifugation, re-suspended in lysis buffer (20 $\mathrm{mM}$ Tris, $\mathrm{pH}$ 8.0, $200 \mathrm{mM} \mathrm{NaCl}$ ), and lysed by sonication on ice. After removing cell debris by centrifugation $(25,000 \times \mathrm{g}$ for $0.5 \mathrm{~h}$ at $4^{\circ} \mathrm{C}$ ), the supernatant containing soluble protein was purified using HisTrap HP column (Cytiva) and HiLoad 16/60 Superdex 200 pg column (Cytiva). The elution profile of the protein showed a single major peak and the protein quality was evaluated by SDS-PAGE.

Crystallization, data collection, and structure determination Gel-filtration fractions containing the complex of CD38 and isatuximab Fab were concentrated to $15 \mathrm{mg} \mathrm{ml}^{-1}$ in $20 \mathrm{mM}$
Tris, $\mathrm{pH} 8.0$, and $300 \mathrm{mM} \mathrm{NaCl}$. Initial crystallization of the protein was performed with commercially available screening solutions (Hampton Research) by the hanging-drop vapordiffusion method at $20^{\circ} \mathrm{C}$. In the initial crystallization screening experiments, $0.8 \mu \mathrm{l}$ of protein solution was mixed with $0.8 \mu \mathrm{l}$ of reservoir solution and equilibrated against $300 \mu$ of the reservoir solution. Crystals were grown with a reservoir solution containing $0.2 \mathrm{M}$ Ammonium phosphate monobasic, $0.1 \mathrm{M}$ Tris, $50 \%(\mathrm{v} / \mathrm{v})$ 2-Methyl-2,4-pentanediol (MPD), $\mathrm{pH} 8.5$ at $20^{\circ} \mathrm{C}$ within a week. Crystals were cryoprotected by brief immersion in well solution supplemented with $25 \%$ ethylene glycol, and flash frozen in liquid nitrogen. X-ray diffraction data were collected at $100 \mathrm{~K}$ on beamline $11 \mathrm{C}$ of the Pohang Light Source (PLS) to a resolution of $1.90 \AA$, integrated and scaled using HKL2000 (HKL Research). The structure was solved by molecular replacement using Phaser with the structures of an antibody Fab (PDB code 5veb, chains $A$ and $B$ ) and CD38 (PDB code 5bni) as search models (McCoy et al., 2007). Because of the intrinsic flexibility of the Fab elbow within an antibody, the variable and constant regions of the Fab were separated during MR search. After MR phasing, the electron density corresponding to the complex was prominent in the asymmetric unit. Iterative model building and structure refinement are currently in progress using PHENIX with manual inspection using COOT (Adams et al., 2010; Emsley and Cowtan, 2004).

\section{ACKNOWLEDGEMENTS}

We are grateful to the staff of beamline $11 \mathrm{C}$ at Pohang Accelerator Laboratory for help with the X-ray diffraction experiments. This work was supported by a grant from the National Research Foundation of Korea (NRF-2020R1A2C2008865).

\section{CONFLICT OF INTEREST}

The authors declare no conflict of interest.

\section{AUTHOR INFORMATION}

H.T.L., Y.K., U.B.P., and T.J.J performed the experiments. Y.S.H. wrote the paper. All authors discussed the results and commented on the manuscript.

Original Submission: Dec 7, 2020

Revised Version Received: Dec 18, 2020

Accepted: Dec 18, 2020

\section{REFERENCES}

Adams, P.D., Afonine, P.V., Bunkóczi, G., Chen, V.B., Davis, I.W., Echols, N., Headd, J.J., Hung, L.W., Kapral, G.J., Grosse-Kunstleve, R.W., McCoy, A.J., Moriarty, N.W., Oeffner, R., Read, R.J., Richardson, D.C., et al. (2010). PHENIX: a comprehensive Python-based system for macromolecular structure solution. Acta Crystallogr D Biol Crystallogr 66, 213-221.

Bonello, F., D’Agostino, M., Moscvin, M., Cerrato, C., Boccadoro, M., and Gay, F. (2018). CD38 as an immunotherapeutic target in multiple 
myeloma. Expert Opin Biol Ther 18, 1209-1221.

Deckert, J., Wetzel, M.C., Bartle, L.M., Skaletskaya, A., Goldmacher, V.S., Vallée, F., Zhou-Liu, Q., Ferrari, P., Pouzieux, S., Lahoute, C., Dumontet, C., Plesa, A., Chiron, M., Lejeune, P., Chittenden, T., et al. (2014). SAR650984, a novel humanized CD38-targeting antibody, demonstrates potent antitumor activity in models of multiple myeloma and other CD38+ hematologic malignancies. Clin Cancer Res 20, 4574-4583.

de Weers, M., Tai, Y.T., van der Veer, M.S., Bakker, J.M., Vink, T., Jacobs, D.C., Oomen, L.A., Peipp, M., Valerius, T., Slootstra, J.W., Mutis, T., Bleeker, W.K., Anderson, K.C., Lokhorst, H.M., van de Winkel, J.G., et al. (2011). Daratumumab, a novel therapeutic human CD38 monoclonal antibody, induces killing of multiple myeloma and other hematological tumors. J Immunol 186, 1840-1848.

Dhillon, S. (2020). Isatuximab: first approval. Drugs 80, 905-912.

Emsley, P., and Cowtan, K. (2004). Coot: model-building tools for molecular graphics. Acta Crystallogr D Biol Crystallogr 60, 2126-2132.

Lee, J.Y., Lee, H.T., Shin, W., Chae, J., Choi, J., Kim, S.H., Lim, H., Heo, T.W., Park, K.Y., Lee, Y.J., Ryu, S.E., Son, J.Y., Lee, J.U., and Heo, Y.S. (2016). Structural basis of checkpoint blockade by monoclonal antibodies in cancer immunotherapy. Nat Commun 7, 13354.

Martin, T.G., Corzo, K., Chiron, M., Velde, H.V., Abbadessa, G., Campana, F., Solanki, M., Meng, R., Lee, H., Wiederschain, D., Zhu, C., Rak, A., and
Anderson, K.C. (2019). Therapeutic opportunities with pharmacological inhibition of CD38 with isatuximab. Cells 8, 1522.

Matthews, B.W. (1968). Solvent content of protein crystals. J Mol Biol 33, 491-497.

McCoy, A.J., Grosse-Kunstleve, R.W., Adams, P.D., Winn, M.D., Storoni, L.C., and Read, R.J. (2007). Phaser crystallographic software. J Appl Crystallogr 40, 658-674.

McKeage, K. (2016). Daratumumab: first global approval. Drugs 76, 275281.

Moreno, L., Perez, C., Zabaleta, A., Manrique, I., Alignani, D., Ajona, D., Blanco, L., Lasa, M., Maiso, P., Rodriguez, I., Garate, S., Jelinek, T., Segura, V., Moreno, C., Merino, J., et al. (2019). The mechanism of action of the anti-CD38 monoclonal antibody isatuximab in multiple myeloma. Clin Cancer Res 25, 3176-3187.

Palumbo, A., Chanan-Khan, A., Weisel, K., Nooka, A.K., Masszi, T., Beksac, M., Spicka, I., Hungria, V., Munder, M., Mateos, M.V., Mark, T.M., Qi, M., Schecter, J., Amin, H., Qin, X., et al. (2016). Daratumumab, bortezomib, and dexamethasone for multiple myeloma. $N$ Engl J Med 375, 754-766.

van de Donk, N., Richardson, P.G., and Malavasi, F. (2018). CD38 antibodies in multiple myeloma: back to the future. Blood 131, 13-29. 